\title{
Milliequivalent per Gram
}

National Cancer Institute

\section{Source}

National Cancer Institute. Milliequivalent per Gram. NCI Thesaurus. Code C70580.

A unit of relative amount of substance content equivalent to the content at which one gram of mixture contains one thousandth of an equivalent of a component. The unit is also used as a dose calculation unit. 